\title{
Turmeric and curcumin suppress presenilin 1 protein expression in Jurkat cells
}

\author{
HITOMI YOSHIDA*, NAOKO OKUMURA*, YURI NISHIMURA, YASUKO KITAGISHI and SATORU MATSUDA \\ Department of Environmental Health Science, Nara Women's University, Nara 630-8506, Japan
}

Received March 15, 2011; Accepted March 31, 2011

DOI: 10.3892/etm.2011.246

\begin{abstract}
In the present study, we aimed to determine the effects of herbs or spices on the expression of presenilin 1 , a molecule involved in $\gamma$-secretase activity and the generation of amyloid- $\beta$ peptide in Alzheimer's disease. Western blot analysis revealed that presenilin 1 protein expression was down-regulated by stimulation with turmeric or cinnamon extracts in vitro, while the effects on presenilin 1 gene expression examined by reverse transcriptase-polymerase chain reaction were unaltered. Our results showed that curcumin, a component of turmeric, induced the down-regulation of presenilin 1 protein in Jurkat and K562 cell lines.
\end{abstract}

\section{Introduction}

Alzheimer's disease is a neurodegenerative disease caused by amyloid- $\beta$ accumulation in brain cells combined with oxidative stress and inflammation $(1,2)$. Neurotoxic amyloid- $\beta$ is an approximately $4-\mathrm{kDa}$ peptide generated via cleavage of the amyloid- $\beta$ precursor protein (APP) by the $\gamma$-secretase proteolytic complex (3). Presenilin is the catalytic member of the $\gamma$-secretase complex, and mutations in presenilin are the major cause of early-onset familial Alzheimer's disease. Presenilin is involved in several biological functions, but is well known for its role in the generation of the amyloid- $\beta$ peptide in Alzheimer's disease and is therefore thought to be an important drug target for this disorder. Thus, an increased understanding of Presenilin may help to improve the development of drugs for Alzheimer's disease and for other neurological diseases (4).

Certain herbs have been demonstrated to possess a multitude of beneficial activities, and herbal medications are

Correspondence to: Dr Satoru Matsuda, Department of Environmental Health Science, Nara Women's University, Kita-Uoya, Nishimachi, Nara 630-8506, Japan

E-mail: smatsuda@cc.nara-wu.ac.jp

*Contributed equally

Key words: presenilin 1, turmeric, curcumin, Alzheimer's disease, down-regulation currently being used for widespread clinical use in disease therapy, as herbs exhibit relatively mild bioavailability and low toxicity (5). As for Alzheimer's disease, polyphenols extracted from grape seeds have been found to inhibit amyloid- $\beta$ aggregation, reduce amyloid- $\beta$ production and protect against amyloid- $\beta$ neurotoxicity in vitro $(6,7)$. In addition, cryptotanshinone (CTS), an active component of the medicinal herb Salvia miltiorrhiza, has been shown to improve learning and memory in several pharmacological models of Alzheimer's disease (8). Further research demonstrated that CTS improved the cognitive ability and promoted APP metabolism involving the non-amyloidogenic product pathway in rat cortical neuronal cells. Moreover, as the Indian diet is rich in herbs and spices, the incidence of Alzheimer's disease in India is considerably low $(9,10)$. However, the precise molecular mechanisms of the therapeutic effects of medicinal herbs and spices are largely undefined, and limited data and a small body of convincing evidence exist at the molecular level (11). Therefore, basic research and development aimed at elucidating the mechanism of action underlying herbal effects should have high priority. We hypothesized that various herbs or spices may affect the $\gamma$-secretase proteolytic function. Therefore, we investigated the in vitro effect of several herbs on the expression of presenilin 1 in cultured human cells.

\section{Materials and methods}

Cell culture. The human cell lines, Jurkat, Daudi, U937 and K562, were maintained in RPMI-1640 supplemented with $10 \%$ fetal bovine serum (FBS), penicillin and streptomycin at $37^{\circ} \mathrm{C}$ in a humidified atmosphere containing $5 \% \mathrm{CO}_{2}$.

Extract preparation. Herb and spice powders were purchased at a food market in Japan. The powders were dissolved in $80 \%$ ethanol and subsequently diluted in $40 \%$ ethanol at a stock concentration of $50 \mathrm{mg} / \mathrm{ml}$. The mixtures were vortexed rigorously for $3 \mathrm{~min}$ followed by 3 -min sonication. After centrifugation $(1,500 \mathrm{x} \mathrm{g}, 5 \mathrm{~min})$, the supernatants were collected and stored at $-20^{\circ} \mathrm{C}$ until use. For the cell treatments, a range of $0.5-10 \mu \mathrm{l}$ was added to $1 \mathrm{ml}$ of the cell culture medium.

Reverse transcriptase-polymerase chain reaction (RT-PCR). Presenilin 1 and GAPDH mRNAs were analyzed by semiquantitative RT-PCR. Total RNA was extracted by an 


\section{$\begin{array}{lllllllll}M & 1 & 2 & 3 & 4 & 5 & 6 & 7 & 8\end{array}$

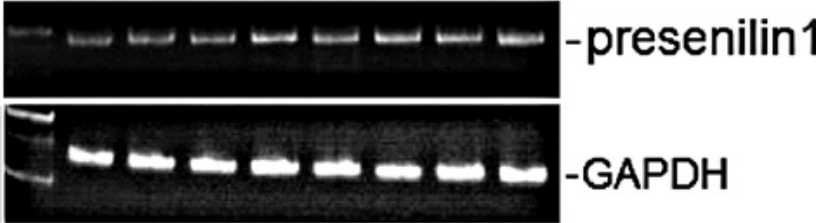

Figure 1. Semi-quantitative RT-PCR was performed using primers specific to presenilin 1 or GAPDH using $100 \mathrm{ng}$ total RNA prepared from Jurkat cells treated without (lane 1) or with herbal extracts (lanes 2-8: garlic, red pepper, cinnamon, phakchi, turmeric, basil and black pepper, respectively) at a final concentration of $50 \mu \mathrm{g} / \mathrm{ml}$ for $24 \mathrm{~h}$. Specific expression was determined in relation to the expression of the housekeeping gene GAPDH used as an internal loading control. At least four independent experiments were performed, and typical paired results are documented.

RNA isolation kit (Takara, Japan). Total RNA $(2 \mu \mathrm{g})$ was reverse-transcribed using the Phusion RT-PCR kit (NEB) as described in the manufacturer's protocol. Cycle-based PCR was used to semi-quantitate the presenilin 1 gene level. GADPH was also used as an internal loading control. All the samples were evaluated within 3 months after collection. The primers used for the PCR were: presenilin 1 forward, GGTCCACTTCGTATGCTGGT and reverse, GCTGTTGCTGAGGCTTTACC (expected size 404 bp); GAPDH forward, TCCCATCACCATCTTCCA and reverse, CATCACGCCACAGTTTCC (expected size 376 bp). For real-time PCR, the reactions were performed in a real-time PCR system (Illumina, USA) using Kapa SYBR Fast reaction mix (Genetics, Japan). Thermocycling was performed according to the instructions at an annealing temperature of $60^{\circ} \mathrm{C}$ in a final volume of $10 \mu \mathrm{l}$, including Taq DNA polymerase. To correct for differences in both RNA quality and quantity between samples, data were normalized using the ratio of the target cDNA concentration to that of GAPDH.

Western blot analysis. Equal amounts of protein samples were used for Western blot analysis using anti-presenilin 1 (Genscript) and anti-Erk2 (Epitomics) antibodies, and quanti- fied by densitometry. The Western blotting was repeated at least three times, and the representative data are shown.

\section{Results and discussion}

To investigate the possibility of using medicinal herbs to down-regulate presenilin 1 protein, extracts of many herbs and spices, including garlic, red pepper, cinnamon, phakchi, turmeric, basil and black pepper, were added to the cell culture medium of Jurkat, Daudi, U937 or K562 cells, and the levels of genes, including presenilin 1, were examined. RT-PCR analysis was employed to quantify the expression level of the genes. Total RNA was isolated $24 \mathrm{~h}$ after herbal extract treatment for the detection of presenilin 1, and the levels of presenilin 1 mRNA were determined by conventional semiquantitative RT-PCR. As shown in Fig. 1, the expression level of the presenilin 1 gene was not altered by treatment of the herbal and spice extracts at a final concentration of $50 \mu \mathrm{g} /$ $\mathrm{ml}$, compared to the untreated ethanol vehicle. Expression of presenilin 2 (data not shown) and the housekeeping gene GAPDH were also unaltered (Fig. 1). In addition, similar results were also obtained from the quantitative real-time PCR analysis (Fig. 2). There was little difference in the results of the gene expressional profile among the Jurkat, Daudi, U937 and K562 cells (data not shown). To exclude the possibility of carry-over DNA contamination, reactions containing all RT-PCR reagents, including primers without sample RNA, were performed as negative controls. No such RNA contamination was detected (data not shown).

To further examine the status of the level of protein expression, Western blotting was performed to analyze the presenilin 1 protein in the cells stimulated by the herbs and spices. As shown in Fig. 3, the turmeric and cinnamon extract dramatically reduced the protein expression of presenilin 1 in the Jurkat cells when the cell cultures were treated with the spices for $48 \mathrm{~h}$. The down-regulation of presenilin 1 protein expression by the several herbal extracts was in approximate accord with the result of the long-term-treated cells $(72 \mathrm{~h}$ after herbal stimulation) (Fig. 3, lower panels). After long-term stimulation,

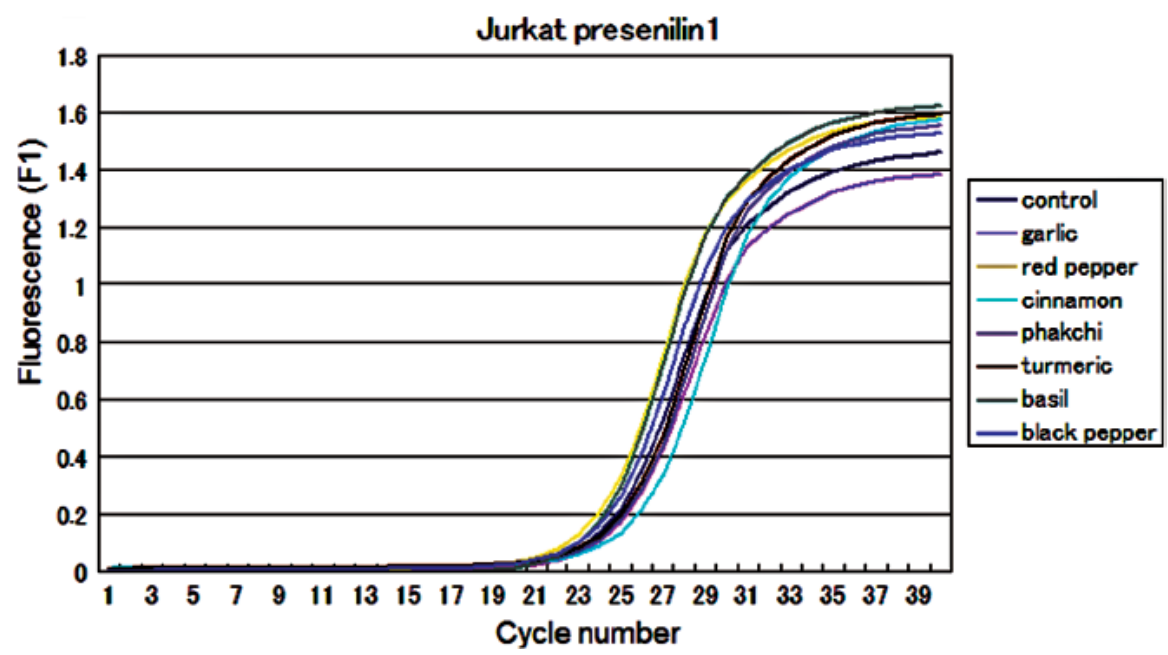

Figure 2. Fluorescence data for PCR amplification plots of presenilin 1 in Jurkat cells stimulated by the indicated herbs and spices. Data were generated by Thermal-Cycler software using the Illumina Real-Time PCR Detection system. No product was amplified in the no-template sample or when reverse transcriptions were omitted. Similar results were obtained when the PCR products of Daudi and K562 cells were analyzed. 


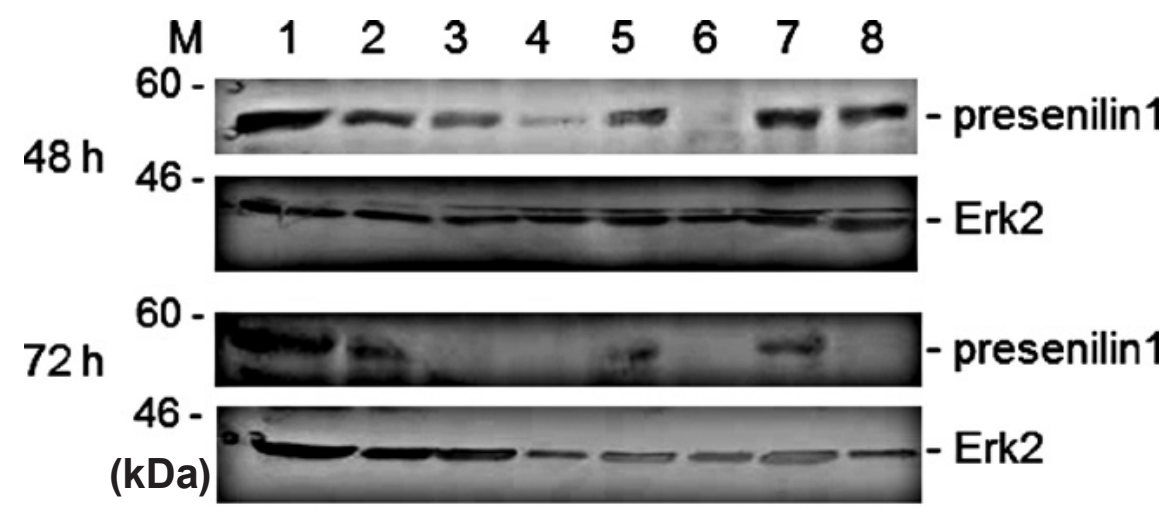

Figure 3. Turmeric and cinnamon extract reduced the expression of presenilin 1 protein. (A) Jurkat cells were treated without (lane 1) or with extracts of herbs (lanes 2-8: garlic, red pepper, cinnamon, phakchi, turmeric, basil and black pepper, respectively) at a final concentration of $50 \mu \mathrm{g} / \mathrm{ml}$ for 48 or $72 \mathrm{~h}$. After treatment, cell lysates were isolated and the levels of presenilin 1 protein were detected by Western blot analysis using an anti-presenilin 1 antibody. Western blots with an anti-Erk2 antibody were also shown as controls for equal levels of protein loading. At least three independent experiments were performed and typical paired results are shown.

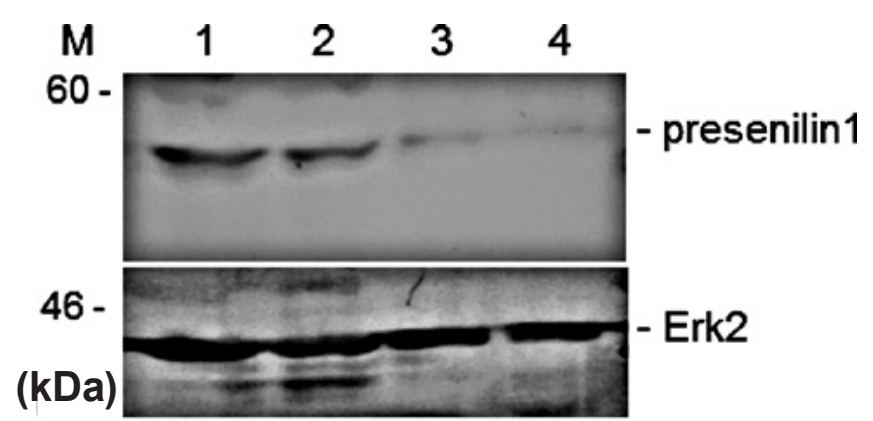

Figure 4. Dose-dependent inhibition of presenilin 1 protein expression by curcumin. Jurkat cells were treated without (lane 1) or with curcumin extracts at a final concentration of 25 (lane 2), 50 (lane 3) and $100 \mu \mathrm{g} / \mathrm{ml}$ (lane 4) for $48 \mathrm{~h}$. The levels of protein were detected by Western blot analysis using an anti-presenilin 1 antibody as explained in Fig. 3. Western blotting with an anti-Erk2 antibody was also shown as a control for equal levels of protein loading.

it was evident that red and black pepper, in addition to turmeric and cinnamon, down-regulated presenilin 1 protein expression. We then investigated whether curcumin, a major component of turmeric, reduces presenilin 1 expression. After treating the cells with different concentrations of curcumin, presenilin 1 protein, but not Erk2 protein expression was decreased with increasing concentrations of the curcumin extract. A final concentration of $100 \mu \mathrm{g} / \mathrm{ml}$ of the curcumin extract inhibited expression of presenilin 1 by $>95 \%$ in the Jurkat cells (Fig. 4). The turmeric extract also down-regulated presenilin 1 in a dose-dependent manner in the K562 cells (data not shown).

A recent in vivo study demonstrated that curcumin was able to reduce amyloid- $\beta$-related pathology in transgenic Alzheimer's disease mouse models via unknown molecular mechanisms (12). Curcumin is a small-molecule fluorescent compound found in the widely used culinary spice, turmeric, which possesses potent biological activities, including antiinflammatory, anti-fibrilogenic and antioxidant, as well as chemopreventative effects and effects on protein trafficking. Curcumin has also been found to lower amyloid- $\beta$ protein levels by attenuating the maturation of APP in the secretory pathway. Curcumin was demonstrated to promote a signifi- cant reversal of structural changes in dystrophic dendrites, including abnormal curvature and dystrophy size (13). The computed ionization potential and electron affinity show that curcumin has a low-molecular hardness, and the resulting charge undergoes delocalization throughout the structure, resulting in excitonic features. This feature appears to be important for its binding capability to human proteins, such as human serum albumin and amyloid- $\beta$ (14). Together, these data suggest that curcumin reverses Alzheimer's disease pathology and propose a mechanism of action for the ability of curcumin to attenuate amyloid- $\beta$ pathology. This approach may lead to more effective clinical therapies for the prevention of oxidative stress, inflammation and neurotoxicity associated with Alzheimer's disease.

In the present study, curcumin and the other spice components dose-dependently down-regulated presenilin 1 protein, which plays a pivotal role in $\gamma$-secretase activity. Recently, ubiquilin-1 was reported to regulate the proteasomal degradation of proteins, including presenilin (15). Since the proteasome is responsible for the removal of oxidatively damaged proteins in the cytosol and nucleus during oxidative stress (16), it is plausible that presenilin 1 protein may be degraded by the ubiquitin proteasome pathway (17). Various herbs and spices may accelerate this degradation. Further study including in vivo experiments must be undertaken to elucidate the precise molecular mechanisms of these herbs particularly in regard to the treatment of Alzheimer's disease.

\section{Acknowledgements}

This study was supported by grants-in-aid from the Ministry of Education, Culture, Sports, Science and Technology of Japan, and the Nara Women's University Intramural Grant for Project Research.

\section{References}

1. Bekris LM, Yu CE, Bird TD and Tsuang DW: Genetics of Alzheimer disease. J Geriatr Psychiatry Neurol 23: 213-227, 2010.

2. Ittner LM and Götz J: Amyloid- $\beta$ and tau - a toxic pas de deux in Alzheimer's disease. Nat Rev Neurosci 12: 65-72, 2011. 
3. Woo HN, Baik SH, Park JS, Gwon AR, Yang S, Yun YK and Jo DG: Secretases as therapeutic targets for Alzheimer's disease. Biochem Biophys Res Commun 404: 10-15, 2011.

4. Crews L, Rockenstein E and Masliah E: APP transgenic modeling of Alzheimer's disease: mechanisms of neurodegeneration and aberrant neurogenesis. Brain Struct Funct 214: 111-126, 2010.

5. Al-Mofleh IA: Spices, herbal xenobiotics and the stomach: friends or foes? World J Gastroenterol 16: 2710-2719, 2010.

6. Wang YJ, Thomas P, Zhong JH, Bi FF, Kosaraju S, Pollard A, Fenech $\mathrm{M}$ and Zhou XF: Consumption of grape seed extract prevents amyloid-beta deposition and attenuates inflammation in brain of an Alzheimer's disease mouse. Neurotox Res 15: 3-14, 2009.

7. Thomas P, Wang YJ, Zhong JH, Kosaraju S, O'Callaghan NJ, Zhou XF and Fenech M: Grape seed polyphenols and curcumin reduce genomic instability events in a transgenic mouse model for Alzheimer's disease. Mutat Res 661: 25-34, 2009.

8. Mei Z, Zhang F, Tao L, Zheng W, Cao Y, Wang Z, Tang S, Le K, Chen S, Pi R and Liu P: Cryptotanshinone, a compound from Salvia miltiorrhiza modulates amyloid precursor protein metabolism and attenuates beta-amyloid deposition through upregulating alpha-secretase in vivo and in vitro. Neurosci Lett 452: 90-95, 2009.

9. Kelloff GJ, Crowell JA, Steele VE, Lubet RA, Malone WA, Boone CW, Kopelovich L, Hawk ET, Lieberman R, Lawrence JA, Ali I, Viner JL and Sigman CC: Progress in cancer chemoprevention: development of diet-derived chemopreventive agents. J Nutr 130: S467-S471, 2000.

10. Ganguli M, Chandra V, Kamboh MI, Johnston JM, Dodge HH, Thelma BK, Juyal RC, Pandav R, Belle SH and DeKosky ST: Apolipoprotein $\mathrm{E}$ polymorphism and Alzheimer disease: the Indo-US Cross-National Dementia Study. Arch Neurol 57: 824-830, 2000
11. Okumura N, Nishimura Y, Yoshida H, Nagata Y, Kitagishi Y and Matsuda S: Ethanol extract of herb Sage suppressed the TIMP-1 expression in lymphoid culture cells. Asia J Sci Technol 3: 64-66, 2010.

12. Zhang C, Browne A, Child D and Tanzi RE: Curcumin decreases amyloid-beta peptide levels by attenuating the maturation of amyloid-beta precursor protein. J Biol Chem 285: 28472-28480, 2010.

13. Garcia-Alloza M, Borrelli LA, Rozkalne A, Hyman BT and Bacskai BJ: Curcumin labels amyloid pathology in vivo, disrupts existing plaques, and partially restores distorted neurites in an Alzheimer mouse model. J Neurochem 102: 1095-1104, 2007.

14. Balasubramanian K: Molecular orbital basis for yellow curry spice curcumin's prevention of Alzheimer's disease. J Agric Food Chem 54: 3512-3520, 2006.

15. Viswanathan J, Haapasalo A, Böttcher C, et al: Alzheimer's disease-associated ubiquilin-1 regulates presenilin-1 accumulation and aggresome formation. Traffic 12: 330-348, 2011.

16. Breusing $\mathrm{N}$ and Grune T: Regulation of proteasome-mediated protein degradation during oxidative stress and aging. Biol Chem 389: 203-209, 2008.

17. Magini A, Urbanelli L, Ciccarone V, Tancini B, Polidoro M, Timperio AM, Zolla L, Tedde A, Sorbi S and Emiliani C: Fibroblasts from PS1-mutated pre-symptomatic subjects and Alzheimer's disease patients share a unique protein level profile. J Alzheimers Dis 21: 431-444, 2010. 